\title{
A MORPHOLOGICAL STUDY OF PATENT FORAMEN OVALE IN SUDANESE POPULATION
}

\author{
Ahmed Mohammad Atiaallah Mohammad Kkair ${ }^{1}$, Ali Yasen Yasen Mohamed Ahmed ${ }^{2}$, Mutaz Ogeal Osman ${ }^{3}$, \\ Mawadda Farah Ismail ${ }^{4}$, Khalid Elamin Awad ${ }^{5}$ \\ 1 Assistant Professor of Surgery - Red Sea University - Sudan. \\ 2 General Surgeon, SMSB -Sudan. \\ 3 Assistant professor of Anatomy, Red Sea University-Sudan. \\ 4 Teaching assistant, Red Sea University -Sudan. \\ 5 Head of department of Anatomy, University of Khartoum - Sudan. \\ Correspondence to Dr Ali Yasen Yasen Mohamedahmed, MBBS, MSc, MD, MRCS. P.O. Box 102, \\ Alqasr Avenue, Khartoum 11111, Sudan. Email: dr.aliyasen1@gmail.com.
}

\section{ABSTRACT}

The aim of this study is to establish anatomical reference regarding PFO among Sudanese as increasing evidence was found that PFO is culprit in paradoxical emboli events; this led to the reevaluation of this relatively important anomaly. We included 60 apparently normal hearts available in Dissection Rooms in five faculties of medicine in Sudan. The rate of PFO was $7(11.7 \%)$ and the diameter was ranging between $5 \mathrm{~mm}$ and $21 \mathrm{~mm}$, with average of $0.87 \mathrm{~mm}$. We conclude that PFO is common among Sudanese and was seen in seven cadavers (11.7\%).

\section{INTRODUCTION}

Patent foramen ovale (PFO) is a flap like opening between the atrial septa primum and secundum at the location of the fossa ovalis that persists after age of one year (Phibbs, 2007). In utero, the foramen ovale serves as a physiologic conduit for right-to-left shunting. When the pulmonary circulation is established after birth and the fetus takes first breath at birth, pulmonary respiration begins (Moore et al., 2013). This increases the amount of blood traversing via pulmonary trunk into pulmonary arteries and Pulmonary veins in turn carry this oxygenated blood from lungs to the left atrium (Goss, 2010). Shunting of blood to the right side of the heart, builds up pressure in the lungs which form the basis of symptoms of pulmonary hypertension that usually appear in the thirties. A small isolated patent oval foramen is of no hemodynamic significance however, if there are other defects (e.g. pulmonary stenosis or atresia) they may present early in childhood. Blood is shunted through the foramen ovale into left atrium and produce cyanosis; a sign of deficient oxygenation of blood. A probe patent oval foramen is present in up to $25 \%$ of population (Hagen et al.1984). In this condition a probe can be passed from one atrium to other through the foramina, but it is functionally closed. However, this defect is not clinically significant, it's a potential site that may be forced open by co-existing functional pathology of the heart (Sadler, 2011; Rosenthal and Harvey, 2010).

In some instances, patent foramen ovale (PFO) is detectable with color flow Doppler imaging. A small "flame" of colour signal may be seen in the middle region of the atrial septum. Contrast echocardiography is usually required to detect small PFO (Shanks M, 2012).

Most patients with a patent foramen ovale (PFO) as an isolated finding receive no special treatment. No consensus exists on treatment of PFO in patients with transient ischemic attack (TIA) or stroke. When PFO is associated with an otherwise unexplained neurologic event (Steenblik et al., 2009), traditional 
treatment has been antiplatelet (i.e. Aspirin) therapy alone in low-risk patients or combined with warfarin in high-risk individuals to prevent cryptogenic stroke (Polzin A et al., 2015 ; Perk J et al. 2012).

Surgical closure of patent foramen ovale (PFO) with double continuous suture has resulted in elimination of residual shunt across the PFO. Indications include the following: PFO more than $25 \mathrm{~mm}$ in size, inadequate rim of tissue around the defect and Percutaneous device failure (Mirzaali M et al., 2015).

The aim of this study is to establish anatomical reference regarding PFO among Sudanese as increasing evidence was found that PFO is culprit in paradoxical emboli events; this led to the re-evaluation of this relatively important anomaly.

\section{MATERIAL AND METHODS}

This study was conducted on 60 apparently normal hearts available in Dissection Rooms in five faculties of medicine in Sudan. We include all the cadavers or hearts that have not been dissected before and all specimens used were formalin fixed. Exposure of the heart after opening the thoracic cage was done following classical incision and dissection procedures (Penther, 1994). The chambers of the heart were opened to study the interior. In the right atrium, the foramen ovale was noticed. All other chambers were also opened and studied. The measurements were taken using tissue forceps, small probe and tape.

\section{RESULTS}

This study included 60 cadavers where 7 $(11.7 \%)$ of them showed presence of PFO while 53 of them were negative. Measurements of diameter of PFO in this study range was between $5 \mathrm{~mm}$ and $21 \mathrm{~mm}$, with average of $0.87 \mathrm{~mm}$. Associated aberrant cardiac anomalies in was found in one heart in which there was trapped clot in PFO and extending through the right atrium and right ventricle (image 1). Table 1 shows the rate of PFO among different studies (Table 1 ).

Table 1: Rate of PFO among different studies.

\begin{tabular}{|l|l|l|l|}
\hline Study & date & PFO & Country \\
\hline S.D. Joshi et al. 2016. & 2015 & $18 \%$ & India \\
\hline Klimek-Piotrowska W et al. 2016. & 2016 & $24.4 \%$ & Poland \\
\hline Hagen PT et al. 1984. & 1984 & $27 \%$ & USA \\
\hline Penther P 1994. & 1994 & $14.6 \%$ & France \\
\hline This study & 2019 & $11.7 \%$ & Sudan \\
\hline
\end{tabular}




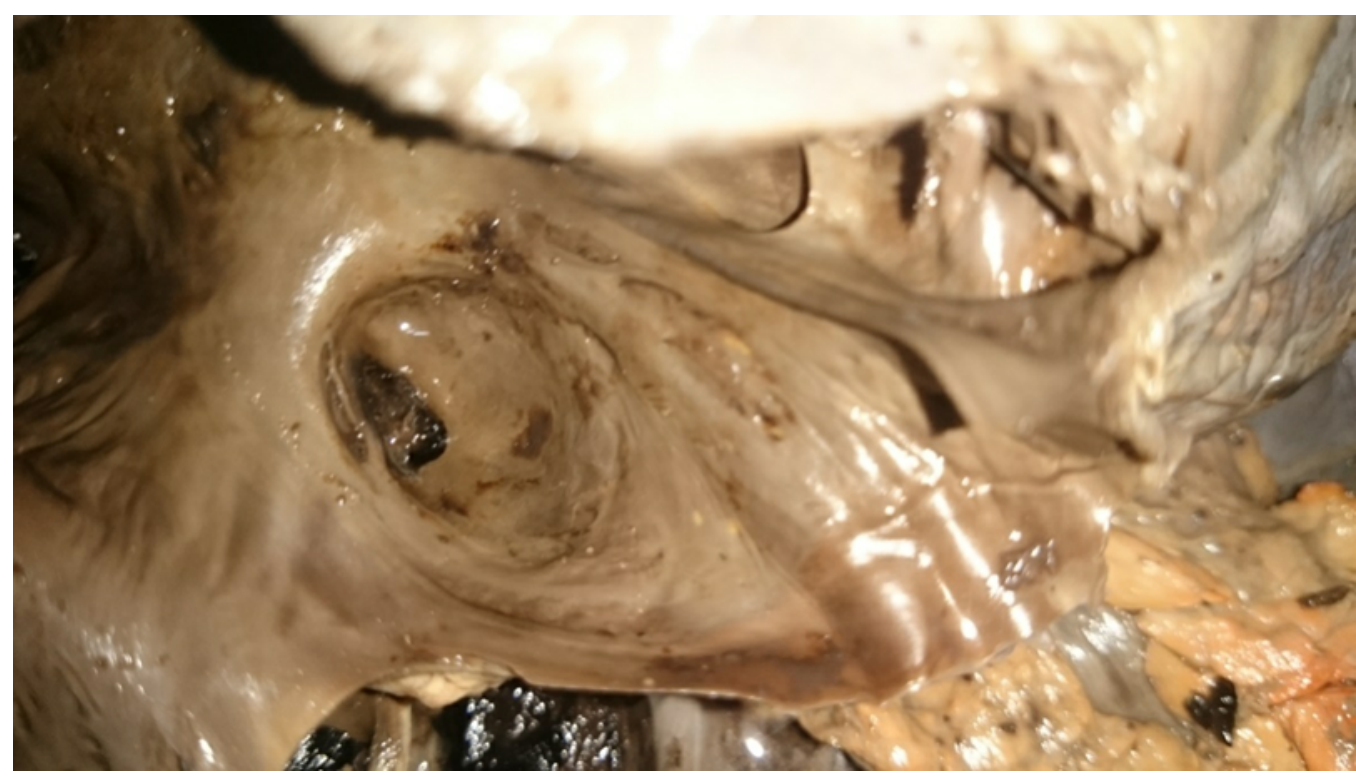

Figure 1: A trapped clot in PFO and extending through the right atrium and right ventricle.

\section{DISCUSSION}

This study included 60 specimens from different medical schools in Khartoum state. Up to our knowledge, there is no similar report neither in Sudan nor in Africa.

In this study the presence of PFO was found to be $11.7 \%$ of Sudanese cadavers. Although there is difference in number of cadavers, our result is similar to a French study done in autopsy of 500 specimens, with a result of 14.6\% PFO (Penther, 1994). However; our obtained results were different from a polish study which revealed a percentage of $24.4 \%$ of PFO in a cadaveric study (Klimek-Piotrowska et al., 2016). The same way, our results are different from radiologic study done in the United State of America in which the prevalence was $27 \% .4$ this difference may be explained by the different methodology that American study was done by echocardiography (Hagen et al., 1984). (Table 1)

The widest diameter of PFO documented in this study was $21 \mathrm{~mm}$ with average $87 \mathrm{~mm}$ and This is similar to the average surface area in a French study which is $5 \mathrm{~mm}$ (range $2 \mathrm{~mm}$ to $15 \mathrm{~mm}$ ) (Penther, 1994). The widest diameter documented in literature was $34 \mathrm{~mm}$ reported in India (Homma et al. , 2005).
Regarding male: female difference, in this study it was difficult to determine because there were no enough available female specimens in most of the studied dissecting rooms. So, the result $96.7 \%$ male and 3.3 female does not reflect true picture. Internationally male to female ratio1:2 (Joshi et al., 2016).

The common associated pathologies reported in literature with PFO were stroke and migraine (Penther, 1994). In this study, I haven't found any aberrant haemorrhage in the brain or other brain anomalies. Due to lack of records and clinical history of cadaveric specimens it was difficult to investigate accurately the association between PFO and other anomalies.

In conclusion, the anatomical knowledge of PFO is important to facilitate the diagnosis and treatment of PFO and enhancement of clinical practice of cardiology. PFO is common among Sudanese and was seen in seven cadavers $(11.7 \%)$ with different diameter ranging from $5 \mathrm{~mm}$ up to $21 \mathrm{~mm}$ with average of $8.7 \mathrm{~mm}$.

We recommend large studies to be taken in both cadavers and living with large sample size 
in African population due to lack of researches

in this particular topic.

\section{CONFLICTS OF INTERESTS: None}

AUTHORS' CONTRIBUTIONS: AMAMK conceived the idea of the study. AMAMK, MOO, AYYM, MFI contributed equally to data collection, data analysis. AMAMK, MOO, AYYM, MFI, KEA contributed to manuscript writing and review of the manuscript. All authors approved the manuscript.

\section{REFERENCES}

1. Goss CM. Gray's Anatomy of the Human Body. Academic Medicine. 2010. 959-1020.

2. Hagen PT, Scholz DG, Edwards WD. Incidence and size of patent foramen ovale during the first 10 decades of life: an autopsy study of 965 normal hearts. In Mayo Clinic Proceedings 1984; 59: 17-20.

3. Homma S, Sacco RL. Patent foramen ovale and stroke. Circulation. 2005. 16; 112(7):10631072.

4. Joshi SD, Chawre HK, Joshi SS. Morphological study of fossa ovalis and its clinical relevance. Indian Heart J. 2016 Mar-Apr;68(2):147-52.

5. Klimek-Piotrowska W, Hołda MK, Koziej M, Piątek K, Hołda J. Anatomy of the true interatrial septum for transseptal access to the left atrium. Ann Anat. 2016; 205:60-4.

6. Mirzaali M, Dooley M, Wynne D, Cooter N, Lee L, Haworth P, Saha R, Gainsborough N, HildickSmith D. Patent foramen ovale closure following cryptogenic stroke or transient ischaemic attack: Long-term follow-up of 301 cases. Catheterization and Cardiovascular Interventions. 2015.15; 86(6):1078-84.

7. Moore KL, Dalley AF, Agur AM. Clinically Oriented Anatomy. Lippincott Williams \&Wilkins; 2013.127-173.

8. Olson E N, Schneider M D. Sizing up the heart: development redux in disease. Genes and development. 2003. 17(16), 1937-1956.

9. Penther P. Patent foramen ovale: an anatomical study. Apropos of 500 consecutive autopsies. Archives des Maladies du Coeur et des Vaisseaux. 1994; 87(1):15-21.

10. Perk J,Backer DE,GohlkeG, Graham D, ReinerI, Verschuren Z, Deaton C. European guidelines on cardiovascular disease prevention in clinical practice (version 2012). European heart journal, 33(13), 1635-1701.

11. Phibbs B. The Human Heart: a Basic Guide to Heart Disease. Lippincott Williams \& Wilkins; 2007.1.

12. Polzin A, Dannenberg L, Popp VS, KelmM, ZeusT. Antiplatelet effects of clopidogrel and aspirin after interventional patent foramen ovale/atrium septum defect closure. 2015. 7:1-5.

13. Rosentha IN, Harvey RP. Heart development and regeneration. Academic Press; 2010. 28.

14. Sadler TW. Langman's Medical Embryology. Lippincott Williams \& Wilkins; 2011.223-273.

15. Shanks M, Manawadu D, Muhll IV, Khan K, Becher H, Choy J. Detection of patent foramen ovale by 3D echocardiography. JACC: Cardiovascular Imaging. 2012. 1; 5(3):329-31.

16. Steenblik MH, Mineau GP, Pimentel R, Michaels AD. Population-based Assessment of Familial Inheritance and Neurologic Co-morbidities among Patients with an Isolated Atrial Septal Defect. Congenital heart disease. 2009. 1; 4(6):459-63. 